\title{
Prognostic Signature of Alternative Splicing Events in Bladder Urothelial Carcinoma Based on Spliceseq Data from 317 Cases
}

\author{
Rong-quan He $\mathrm{a}^{\mathrm{a}, \mathrm{b}, \mathrm{c}, \mathrm{d}, \mathrm{e}}$ Xian-guo Zhou $\mathrm{C}^{\mathrm{a}, \mathrm{b}, \mathrm{c}, \mathrm{d}, \mathrm{e} e}$ Qiao-yong Yia,b,c,d,e \\ Cai-wang Deng ${ }^{a, b, c, c, d, e} \quad J i a-m i n G a O^{a, b, c, c, d e} \quad$ Gang Chen ${ }^{b, c, d, e, f}$ \\ Qiu-yan Wang ${ }^{a, b, c, d, d, e}$
}

\begin{abstract}
aDepartment of Biochemistry and Molecular Biology, Guangxi Medical University, Nanning, Guangxi Zhuang Autonomous Region, ${ }^{b}$ Center for Genomic and Personalized Medicine, Guangxi Medical University, Nanning, Guangxi Zhuang Autonomous Region, 'Guangxi Collaborative Innovation Center for Genomic and Personalized Medicine, Nanning, Guangxi Zhuang Autonomous Region, 'Guangxi Key Laboratory for Genomic and Personalized Medicine, Guangxi Collaborative Innovation Center for Genomic and Personalized Medicine, Nanning, Guangxi Zhuang Autonomous Region, eGuangxi Collaborative Innovation Center for Biomedicine, Guangxi Medical University, Nanning, Guangxi Zhuang Autonomous Region, ${ }^{\text {DDepartment }}$ of Pathology, First Affiliated Hospital of Guangxi Medical University, Nanning, Guangxi Zhuang Autonomous Region, P. R. China
\end{abstract}

\section{Key Words}

Bladder urothelial carcinoma • Splicing event • The Cancer Genome Atlas (TCGA) • Prognosis

\begin{abstract}
Background/Aims: Increasing evidences indicated the important roles of alternative splicing in the progression and prognosis of bladder urothelial carcinoma (BLCA). However, most previous research has focused on one or several alternative splicing events, without a comprehensive evaluation of the prognostic value of splicing events in BLCA. In this study, we aimed to determine risk scores for predicting prognosis of BLCA patients based on splicing events. Methods: RNA-sequencing data and clinical information of BLCA patients were downloaded from The Cancer Genome Atlas, and data of splicing events were obtained from the SpliceSeq database. Univariate and multivariate Cox regression analyses were employed to identify survival-associated alternative spicing events (SASEs) and to calculate risk scores. Protein-protein interaction analysis of genes of the SASEs was performed using STRING, a database of known and predicted protein-protein interactions, and pathway enrichment analysis of the genes was implemented using the Database for Annotation, Visualization and Integrated Discovery (version 6.8). Receiver operating characteristic (ROC) curves and Kaplan-Meier analysis were used to evaluate the clinical significance of genes from the SASEs for building a risk score in BLCA. Correlation between splicing events of splicing factors and
\end{abstract}

Rong-quan He and Xian-guo Zhou contributed equally to this work.

Qiu-yan Wang and Gang Chen
Dept Biochem, Guangxi Medical University 22 Shuangyong Road, Nanning; Dept Pathol, First Affiliated Hospital of Guangxi Medical University، Nanning, Guangxi Zhuang Autonomous Region (P.R. China)

E-Mail qiuyanwang510@yahoo.com, chengang@gxmu.edu.cn 


\section{Cellular Physiology Cell Physiol Biochem 2018:48:1355-1368 and Biochemistry Published online: July 26, $2018 \quad$\begin{tabular}{c|c} 
D 2018 The Authors. \\
www.karger.com/cpb
\end{tabular}}

He et al.: Prognostic Signature of Splicing Events in BLCA

non-splicing factors were analyzed with Pearson correlation coefficient. A potential regulatory network was then built using Cytoscape 3.5. Results: In total, 39,508 alternative splicing events in 317 patients with BLCA were analyzed, including 4,632 SASEs. The area under the curve of the ROC of risk score (all) was 0.748 for predicting survival status of BLCA patients. Low- and high-risk score groups classified using the median "risk score (all)" value displayed remarkably different survival time (Low vs. High $=3304.841 \pm 239.758$ vs $1198.614 \pm 152.460$ days). The potential regulatory network with SASEs of splicing factors and other genes was constructed, which might be part of the biological mechanisms associated with prognosis of BLCA patients. Conclusions: In this study, prognostic signatures constructed using splicing events could be used for predicting the prognosis of BLCA patients.

\section{Introduction}

Proteins are a class of biomacromolecules and are the main constituents of cells and tissues, playing crucial roles in many vital activities. Protein species diversity is the basis of functional diversity. Alternative splicing is a post-transcriptional modification whereby intronic or exonic regions are removed from precursor mRNA, and the multiple combinations achieved by splicing exons together to produce mature RNAs is an important source of protein species diversity [1-4]. Thus, changes in alternative splicing patterns may lead to changes in protein functions and the vital activities based on these functions.

Recently, increasing evidence has shown a close relationship between alternative splicing and tumor occurrence [5]. Alternative splicing has been participated in the mechanisms of tumorigenesis and progression, especially invasion and metastasis of tumor cells [6-9]. In addition, alternative splicing events might serve as biomarkers for cancer diagnosis and treatment, and as potential targets for drug discovery [10].

Splicing factors are the executors of the splicing process. Abnormal expression of splicing factors may cause alterations in splicing events. Indeed, the expression levels of splicing factors differed notably between tumor and normal tissue samples [11]. In some cases, splicing factors may become oncogenes or pseudo-oncogenes and can contribute to tumorigenesis [7].

RNA-sequencing (RNA-seq) techniques and related bioinformatics methods could be used to identify cancer-related alternative splicing [12]. The Cancer Genome Atlas (TCGA) (https://portal.gdc.cancer.gov), supported by the US National Institutes of Health, contains an abundance of data on cancers, including RNA-seq data. SpliceSeq is a resource for RNASeq data from TCGA that provides a clear overview of alternative splicing and identifies splicing events with potential functional changes resulting from splice variations [13]. The SpliceSeq program begins with a standard reference for genes based on the transcripts of protein-coding genes from the Ensemble database. The dataset of SpliceSeq contains seven alternative splicing patterns, namely, exon skip (ES), mutually exclusive exons (ME), retained intron (RI), alternate promoter (AP), alternate terminator (AT), alternate donor site (AD), and alternate acceptor site (AA) [4, 13]. The percent spliced-in index (PSI) value, ranging from zero to one, was introduced to evaluate the transcript ratio of the gene of interest to the seven splicing patterns described above [14].

In the current study, we focused on bladder urothelial carcinoma (BLCA), which is the fourth most common cancer in males and the 11th most common cancer in females, with more than 430, 000 cases annually worldwide [15]. According to the latest epidemiological data on BLCA in the United States, there were 79, 030 new cases in 2017, including 60, 490 males and 18, 540 females, with 16, 870 mortalities, including 12, 240 males and 4, 630 females [16]. BLCA carries a contain poor prognosis owing to the fast progression of the disease. Numerous prognostic factors of BLCA have been discovered, including aberrant microRNAs [17-19] and tumor-associated genes [20-24]. Alternative splicing is also involved in the mechanism of BLCA [25-27] and could be a potential prognostic factor. However, a comprehensive analysis of the prognostic value of alternative splicing events is still lacking. 


\section{Cellular Physiology Cell Physiol Biochem 2018;48:1355-1368

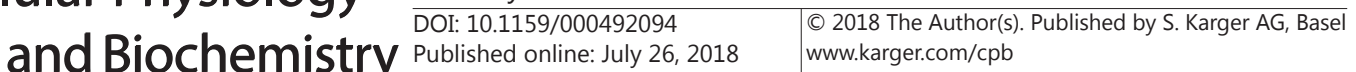

He et al.: Prognostic Signature of Splicing Events in BLCA

In this study, information on BLCA splicing events was obtained from the TCGA SpliceSeq (http://bioinformatics.mdanderson.org/TCGASpliceSeq/). RNA-seq data and clinical information of patients with BLCA were downloaded from TCGA, and 317 patients with survival times of more than 90 days were included in this work. A variety of splicing events associated with survival were discovered, and reliable prognostic signatures with high efficiency for BLCA patients were built.

\section{Materials and Methods}

\section{Data acquisition of alternative splicing events}

Level 3 RNA-seq data and clinical information of BLCA patients were obtained from TCGA. Genomewide splicing events of BLCA were downloaded from the SpliceSeq [13]. A total of 317 patients with survival times of more than 90 days were included in the present study. For each parameter, the 317 BLCA patients were separated into two groups by a median cut.

\section{Construction of the prognostic signature based on survival-associated splicing events}

Univariate Cox regression analysis was performed to identify survival-associated splicing events (SASEs) with P values less than 0.05 . Then, multivariate Cox proportional hazards regression analysis was employed to exclude SASEs that might not be independent predictors for predicting prognosis of BLCA patients. Finally, the prognostic signature, that is, the risk score, for the overall survival (OS) prediction was calculated using the following formula:

$$
\text { Risk score }=\sum_{i}^{n} P S I i * \beta i
$$

Evaluation of the clinical value of risk scores and counterpart genes of splicing events used for prognostic signature construction

The clinical value of risk scores was evaluated by the receiver operating characteristic (ROC) curve and Kaplan-Meier (K-M) analysis. In addition, the mRNA expression data of counterpart genes were obtained from TCGA RNA-seq data. Differential mRNA expression analysis between tumor and para-tumor tissues, ROC curve analysis, and K-M analysis were also performed to evaluate the clinical value of the counterpart genes.

\section{Functional enrichment analyses}

Corresponding genes of the SASEs identified by univariate Cox regression analysis were sent for protein-protein interaction analysis using STRING (https://string-db.org/), a database of known and predicted protein-protein interactions, and for functional enrichment analyses via The Database for Annotation, Visualization and Integrated Discovery (DAVID, version 6.8) (https://david.ncifcrf.gov/), including Gene Ontology (GO) and Kyoto Encyclopedia of Genes and Genomes (KEGG) pathway analysis. An UpSet plot was generated to display the intersections between the seven alternative splicing patterns and the corresponding genes of the SASEs [28].

\section{Construction of the potential regulatory network}

Information for splicing factors was obtained from the SpliceAid2 database (http://www.introni.it/ splicing.html) [29]. Splicing factors differentially expressed between para-tumor and tumor tissues were identified with Student's $t$ test. Correlation analysis was performed between the PSIs of SASEs of splicing factors and mRNA expression data of corresponding splicing factors. To identify the potential regulatory relationship, a second correlation analysis was performed between the PSI value of splicing events of splicing factors and SASEs of non-splicing factors. Cytoscape 3.5 was employed to construct the potential regulatory network. 


\section{Cellular Physiology Cell Physiol Biochem 2018;48:1355-1368 \begin{tabular}{ll|l} 
DOI: 10.1159/000492094 & $\begin{array}{l}\text { () 2018 The Author(s). Published by S. Karger AG, Basel } \\
\text { www.karger.com/cpb }\end{array}$
\end{tabular} \\ He et al.: Prognostic Signature of Splicing Events in BLCA}

Statistical analysis

$\mathrm{K}-\mathrm{M}$ analysis was applied to compare the ability of prognostic signatures to predict outcomes in patients with BLCA. ROC curves were drawn to show the prognostic efficiency of the prognostic signatures. All statistical analyses were performed with Statistical Product and Service Solutions software (IBM Corporation, Version 22, Armonk, NY). P values were obtained from two-sided tests.

\section{Results}

Comprehensive review of mRNA splicing events in BLCA cohort of TCGA

All mRNA splicing events were extensively analyzed based on the SpliceSeq data. A total of 39, 508 mRNA splicing events were detected in 9, 731 genes, including 14, 664 ESs in 6, 005 genes, 2, 618 RIs in 1, 741 genes, 7, 718 APs in 3, 103 genes, 8, 365 ATs in 3, 650 genes, 2, 780 ADs in 1, 967 genes, 3, 201 AAs in 2, 264 genes and 162 MEs in 159 genes (Table 1). These data showed that a single gene might have more than one type of mRNA splicing event. ES was the main type of splicing, with nearly half of the splicing events, while ME was rare, with only 162 splicing events in 159 genes.

\section{SASEs in the BLCA cohort from} TCGA

The profiles of alternative splicing events were analyzed with the univariate Cox proportional hazards regression. The results showed that a total of 4, 632 alternative splicing events in 2, 938 genes were significantly associated with OS $(\mathrm{P}<$ 0.05), including 1, 638 ESs in 1, 270 genes, 545 RIs in 442 genes, 927 APs in 711 genes, 712 ATs in 445 genes, 346 ADs in 309 genes, 444 AAs in 407 genes and 19 MEs in 19 genes (data not shown).

To describe a splicing event precisely, every splicing event was assigned a unique code in the current
Table 1. Overview of alternative splicing events in BLCA

\begin{tabular}{lcc}
\hline Splicing type & Times of splicing event & Gene number \\
\hline ES & 14664 & 6005 \\
RI & 2618 & 1741 \\
AP & 7718 & 3103 \\
AT & 8365 & 3650 \\
AD & 2780 & 1967 \\
AA & 3201 & 2264 \\
ME & 162 & 159 \\
\hline
\end{tabular}

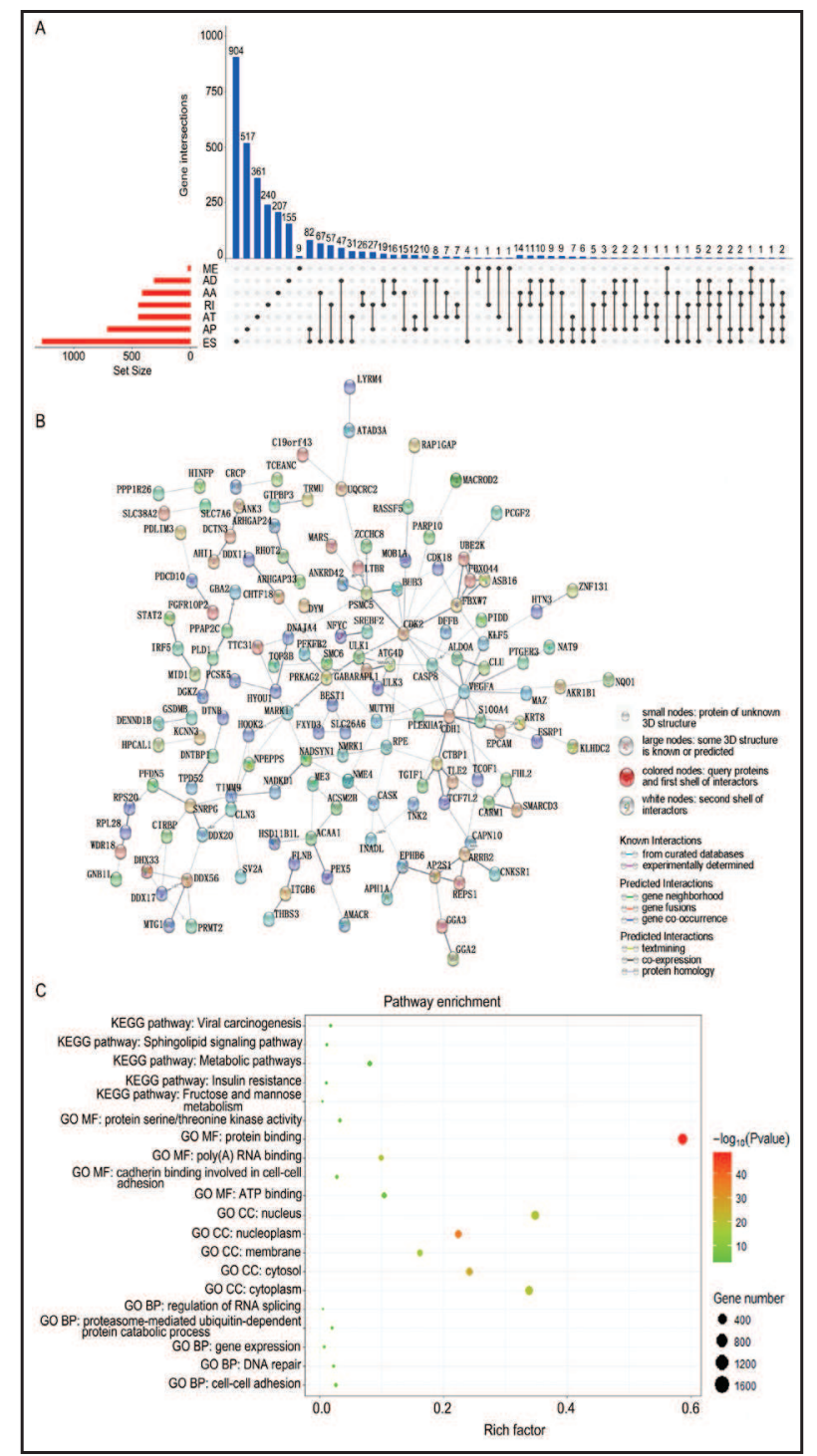

Fig. 1. UpSet plots and bioinformatics analysis with genes from SASEs in BLCA. (A) Schematic of intersections among the seven types of splicing in BLCA by UpSet plot. (B) Protein-protein interaction network of OS-associated genes in BLCA generated by STRING. (C) Top 5 pathways of GO and KEGG analyses of genes from OS-related alternative splicing events. Rich factor represents gene enrichment in a specific pathway. BLCA, bladder urothelial carcinoma. GO, Gene Ontology; KEGG, Kyoto Encyclopedia of Genes and Genomes; CC, cellular component; MF, molecular function; $\mathrm{BP}$, biological process; OS, overall survival. 


\section{Cellular Physiology Cell Physiol Biochem 2018:48:1355-1368 \begin{tabular}{ll|l} 
and Biochemistry & $\begin{array}{l}\text { DOI: 10.1159/000492094 } \\
\text { Published online: July 26, } 2018\end{array}$ & $\begin{array}{l}\text { ( ) } 2018 \text { The Author(s). Published by S. Karger AG, Basel } \\
\text { www.karger.com/cpb }\end{array}$ \\
\hline
\end{tabular} \\ He et al.: Prognostic Signature of Splicing Events in BLCA}

study. For example, for the code CD44ES-5502, CD44 is the gene name, ES is the type of splicing and 5502 is the order number of the splicing event in the dataset.

UpSet plots were drawn to visualize intersecting sets because a single gene may contain 2 or more splicing events remarkably associated with OS, as described above. Lex et al. developed the UpSet plot as a new method to display the intersecting sets simply but more comprehensively than Venn diagrams. As shown in Fig. $1 \mathrm{~A}$, a single gene may contain up to five types of splicing events notably associated with OS. For example, the $\mathrm{AA}, \mathrm{AP}, \mathrm{AT}, \mathrm{ES}$ and RI types of splicing in gene C16orf74 were all prominently associated with OS of BLCA patients. A total of 270 genes from 326 alternative splicing events associated with OS in BLCA $(\mathrm{P}<0.001)$ were uploaded to the STRING website to generate a proteinprotein interaction network. Finally, interactive relationships of 186 genes were shown in Fig. 1B. Hub genes were identified, such as proteasome 26S subunit, ATPase 5 (PSMC5), cyclin dependent kinase 2 (CDK2), vascular endothelial growth factor A (VEGFA), cadherin 1 (CDH1), C-terminal binding protein 1 (CTBP1), caspase 8 (CASP8), ubiquitin conjugating enzyme E2 K

(UBE2K), and F-box and WD repeat domain containing 7 (FBXW7) (Fig. 1B).

Furthermore, 2, 938 genes from 4, 632 OS-associated splicing events were used for bioinformatics analysis with GO and KEGG pathways. A total of 31 pathways were identified in biological processes (BPs) $(\mathrm{P}<0.001)$, such as cell-cell adhesion pathways and regulation of RNA splicing pathways; 18 molecular function (MFs) pathways and 21 cellular component (CC) pathways were also identified $(\mathrm{P}<0.001)$. KEGG analysis reveal a total of 11 remarkably enriched pathways, including medabolic pathways, the fructose Fructose and mannose metabolism pathway, and the viral carcinogenesis pathway $(\mathrm{P}<0.001$, data not shown). The top 5 pathways of GO and KEGG pathway analysis are shown in Fig. 1C.

\section{Construction of the prognostic signature for BLCA patients}

The most significant OS-related splicing events were selected as candidates to construct the prognostic signature for BLCA patients. Risk scores constructed using all splicing types $(\mathrm{P}<0.0001)$, RI-type $(\mathrm{P}<0.005)$, ME-type $(\mathrm{P}<0.05)$, ES-type $(\mathrm{P}<0.005)$, AT-type $(\mathrm{P}<$ 0.005), AP-type ( $<$ 0.001), AD-type $(\mathrm{P}<0.01)$, and AA-type $(\mathrm{P}<0.005)$ SASEs identified by multivariate Cox proportional hazards regression were designated "risk score (all)", "risk score (RI)", "risk score (ME)", "risk score (ES)", "risk score (AT)", "risk score (AP)", "risk score (AD)", and "risk score (AA)",respectively. The computational formulas are provided as follows and in Table 2:

Table 2. Details of splicing events used for constructing the eight risk scores

\begin{tabular}{|c|c|c|c|c|c|c|}
\hline Type & ID & $\beta$ & $\mathrm{HR}$ & Lower & Upper & P value \\
\hline \multirow[t]{8}{*}{ All } & B4GALT2-AA-1228 & -2.311 & 0.099 & 0.034 & 0.293 & $1.12 \mathrm{E}-07$ \\
\hline & TMTC2-ES-9217 & -0.029 & 0.971 & 0.956 & 0.987 & $1.59 \mathrm{E}-06$ \\
\hline & TIMM9-ES-11224 & -0.532 & 0.588 & 0.469 & 0.735 & $3.42 \mathrm{E}-06$ \\
\hline & APOBEC3D-ES-26508 & -0.018 & 0.982 & 0.975 & 0.99 & $2.94 \mathrm{E}-05$ \\
\hline & TPD52-AP-35921 & -0.032 & 0.968 & 0.957 & 0.98 & 0.000272 \\
\hline & MICU1-ES-4164 & 0.876 & 2.401 & 1.498 & 3.848 & 0.000278 \\
\hline & DDX11-ES-8115 & -0.012 & 0.988 & 0.981 & 0.995 & 0.001212 \\
\hline & SMC6-ES-22132 & -0.045 & 0.956 & 0.93 & 0.984 & 0.001811 \\
\hline \multirow[t]{7}{*}{ RI } & ECHDC1-RI-33068 & -0.048 & 0.953 & 0.934 & 0.974 & $9.09 \mathrm{E}-06$ \\
\hline & TMEM159-RI-14269 & -0.016 & 0.984 & 0.976 & 0.992 & $8.46 \mathrm{E}-05$ \\
\hline & NPRL3-RI-13469 & -0.01 & 0.99 & 0.984 & 0.996 & 0.000762 \\
\hline & USP20-RI-37714 & 0.025 & 1.025 & 1.009 & 1.041 & 0.001765 \\
\hline & SSSCA1-RI-6216 & 0.074 & 1.077 & 1.028 & 1.13 & 0.002038 \\
\hline & LCOR-RI-4407 & -0.087 & 0.917 & 0.866 & 0.971 & 0.003104 \\
\hline & ZNF438-RI-3874 & -0.025 & 0.975 & 0.959 & 0.992 & 0.003749 \\
\hline \multirow[t]{4}{*}{ ME } & KHK-ME-22228 & -0.03 & 0.97 & 0.959 & 0.982 & $4.11 \mathrm{E}-07$ \\
\hline & FYN-ME-32979 & 0.022 & 1.022 & 1.008 & 1.036 & 0.001859 \\
\hline & RPE-ME-39176 & -0.018 & 0.982 & 0.97 & 0.993 & 0.001986 \\
\hline & SLC25A3-ME-39308 & -0.348 & 0.706 & 0.564 & 0.883 & 0.002328 \\
\hline \multirow[t]{6}{*}{ ES } & LSR-ES-20521 & -0.031 & 0.97 & 0.955 & 0.985 & 0.00013 \\
\hline & IL2RG-ES-38401 & -0.021 & 0.979 & 0.967 & 0.991 & 0.000558 \\
\hline & ARRB2-ES-15780 & -0.037 & 0.964 & 0.942 & 0.986 & 0.001478 \\
\hline & NQ01-ES-15144 & 0.193 & 1.213 & 1.07 & 1.376 & 0.002617 \\
\hline & RPE-ES-24027 & -0.018 & 0.982 & 0.97 & 0.994 & 0.004585 \\
\hline & BMP1-ES-35381 & -0.12 & 0.887 & 0.816 & 0.964 & 0.004788 \\
\hline \multirow[t]{3}{*}{ AT } & PLD1-AT-28833 & 7.569 & 1937.84 & 93.751 & 40055.1 & $9.66 \mathrm{E}-07$ \\
\hline & PDZRN3-AT-28023 & -0.436 & 0.647 & 0.533 & 0.784 & $8.89 \mathrm{E}-06$ \\
\hline & ARHGAP24-AT-29858 & -0.043 & 0.957 & 0.933 & 0.983 & 0.001192 \\
\hline \multirow[t]{9}{*}{ AP } & CLU-AP-35474 & 0.219 & 1.245 & 1.143 & 1.355 & $4.38 \mathrm{E}-07$ \\
\hline & KCNN3-AP-2403 & 0.068 & 1.071 & 1.035 & 1.108 & $8.67 \mathrm{E}-05$ \\
\hline & MOB1A-AP-22837 & 1.209 & 3.35 & 1.817 & 6.174 & 0.000107 \\
\hline & SLC9B2-AP-29993 & 0.04 & 1.041 & 1.018 & 1.064 & 0.000409 \\
\hline & PDCD10-AP-28790 & 0.649 & 1.914 & 1.331 & 2.753 & 0.000463 \\
\hline & PCGF2-AP-16711 & 0.022 & 1.022 & 1.009 & 1.037 & 0.001372 \\
\hline & LHFPL2-AP-30987 & -0.013 & 0.987 & 0.979 & 0.995 & 0.001486 \\
\hline & MACROD2-AP-24717 & -0.029 & 0.971 & 0.954 & 0.989 & 0.001776 \\
\hline & FBXW7-AP-30279 & -0.013 & 0.987 & 0.978 & 0.996 & 0.00297 \\
\hline \multirow[t]{4}{*}{$\mathrm{AD}$} & FAM73B-AD-37676 & -0.029 & 0.972 & 0.96 & 0.983 & $2.79 \mathrm{E}-06$ \\
\hline & ALS2CL-AD-27456 & -0.012 & 0.988 & 0.982 & 0.994 & 0.0001 \\
\hline & C15orf57-AD-12268 & 0.028 & 1.028 & 1.014 & 1.043 & 0.000157 \\
\hline & SDAD1-AD-29745 & -0.078 & 0.925 & 0.881 & 0.971 & 0.001524 \\
\hline \multirow[t]{10}{*}{$\mathrm{AA}$} & SLC37A4-AA-7336 & -0.032 & 0.969 & 0.958 & 0.979 & $1.53 \mathrm{E}-08$ \\
\hline & NFYC-AA-1101 & -0.103 & 0.903 & 0.863 & 0.944 & $6.99 \mathrm{E}-06$ \\
\hline & ZNF544-AA-21984 & -0.038 & 0.963 & 0.948 & 0.979 & 7.16E-06 \\
\hline & DNAJA4-AA-13165 & -0.036 & 0.965 & 0.949 & 0.981 & $3.98 \mathrm{E}-05$ \\
\hline & MORN2-AA-22424 & -3.662 & 0.026 & 0.004 & 0.164 & 0.00011 \\
\hline & ZMIZ2-AA-33881 & 0.022 & 1.023 & 1.011 & 1.034 & 0.000117 \\
\hline & B4GALT2-AA-1228 & -1.976 & 0.139 & 0.042 & 0.459 & 0.001213 \\
\hline & ALS2CL-AA-27457 & -0.01 & 0.99 & 0.984 & 0.996 & 0.001659 \\
\hline & S100A6-AA-2314 & 0.057 & 1.059 & 1.021 & 1.097 & 0.001808 \\
\hline & IL32-AA-13813 & -0.046 & 0.955 & 0.927 & 0.983 & 0.001942 \\
\hline
\end{tabular}




\section{Cellular Physiology Cell Physiol Biochem 2018;48:1355-1368

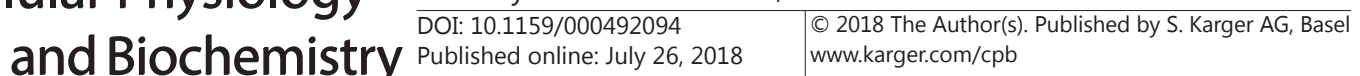

He et al.: Prognostic Signature of Splicing Events in BLCA

Risk score $($ all $)=($ PSI value of B4GALT2-AA-1228 $\times-2.311)+($ PSI value of TMTC2ES-9217 $\times-0.029)+($ PSI value of TIMM9-ES-11224 $\times-0.532)+($ PSI value of APOBEC3DES-26508 $\times-0.018)+($ PSI value of TPD52-AP-35921 $\times-0.032)+($ PSI value of MICU1-ES-4164 $\times 0.876)+($ PSI value of DDX11-ES-8115 $\times-0.012)+($ PSI value of SMC6-ES-22132 $\times-0.045)$.

BLCA patients were classified into low- and high-risk groups based on the median value of the risk score as cut off (Fig. 2). ROC curves were generated to identify the predicted function of patient survival status with these prognostic signatures. The data showed that risk score (all) exhibited the highest efficiency with an area under the curve (AUC) of 0.748, followed by risk score (AP) with an AUC of 0.732 and risk score (RI) with an AUC of 0.702 (Fig. 3, Table 3). K-M curves were employed to analyze the survival times of patients in the low- and high-risk groups. The results showed that survival times differed notably between the two groups in each Cox regression model constructed by all types or each of the seven types of splicing events (Fig. 3, Table 3). Risk score (all) exhibited much more prognostic efficiency compared with the others (Fig. 2, Table 3).

Furthermore, the prognostic value of clinical parameters of patients with BLCA was also analyzed. Univariate Cox proportional hazards regression revealed several parameters that could predict poorer survival of BLCA, including neoplasm cancer status, primary therapy outcome success, pathologic $\mathrm{T}$ stage, pathologic $\mathrm{N}$ stage, pathologic stage, new tumor event after initial treatment, clinical $\mathrm{T}$ stage and risk score (all) (Table 4). However, multivariate

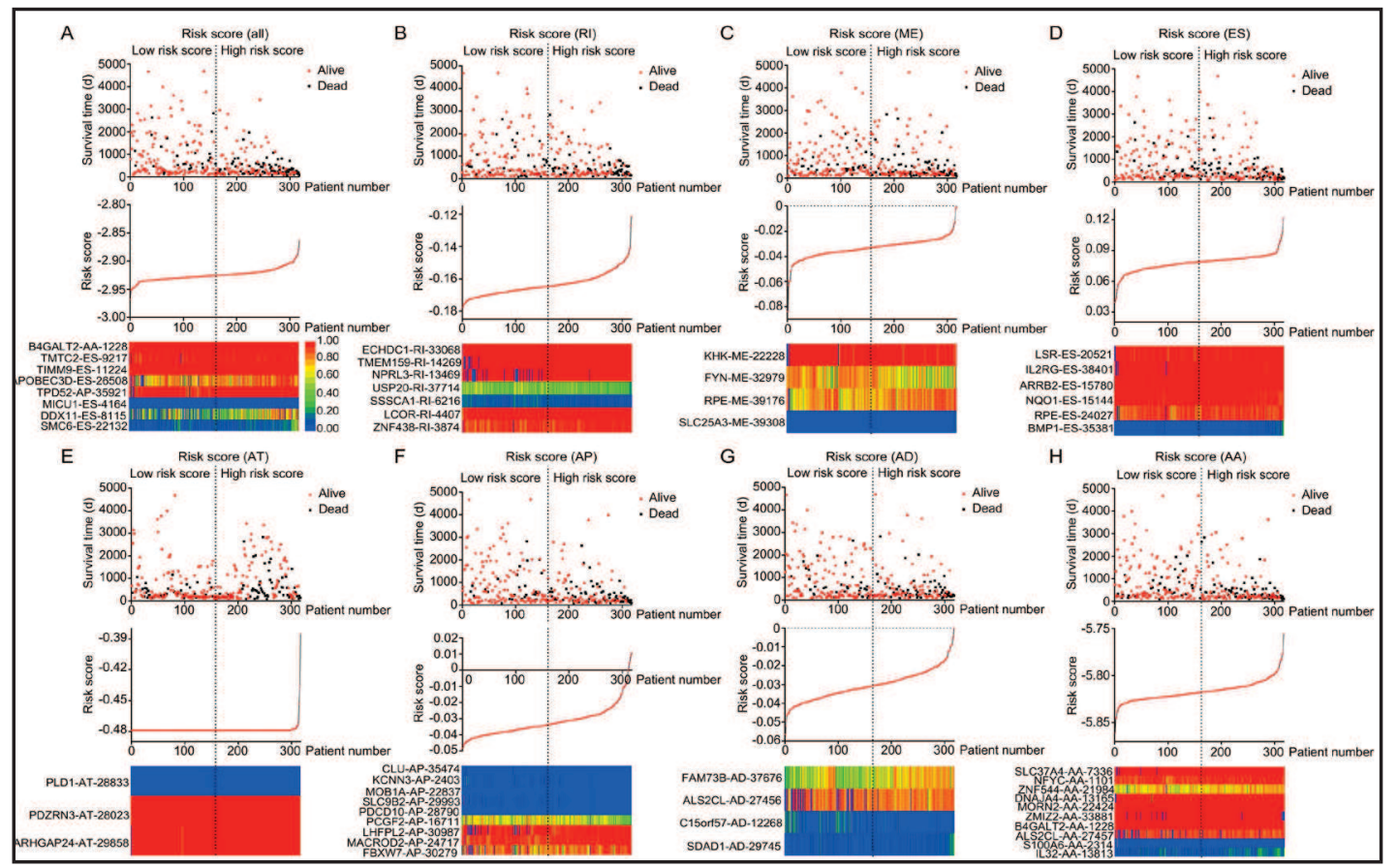

Fig. 2. Construction and analysis of risk score based on the prognosis-associated splicing events using multiple Cox regression analysis. BLCA patients were divided into low- and high-risk groups based on the median value of risk score. The top of each assembly drawing represents survival status and survival time of BLCA patients distributed by risk score, the middle part is the risk score curve of patients with BLCA, and the bottom part shows the heatmap of the PSIs for the ten splicing events. Colors from blue to red indicate increasing PSIs from low to high. (A) Risk scores constructed using all types of prognosis-associated splicing events. (B) Risk scores constructed by RI-type of prognosis-associated splicing events. (C) Risk scores constructed using ME-type of prognosis-associated splicing events. (D) Risk scores constructed using ES-type of prognosis-associated splicing events. (E) Risk scores constructed using AT-type of prognosisassociated splicing events. (F) Risk scores constructed using AP-type of prognosis-associated splicing events. (G) Risk scores constructed using AD-type of prognosis-associated splicing events. (H) risk scores constructed using AA-type of prognostic-associated splicing events. 


\section{Cellular Physiology Cell Physiol Biochem 2018;48:1355-1368 \begin{tabular}{ll|l} 
and Biochemistry $10.1159 / 000492094$ & $\begin{array}{l}\text { (c) 2018 The Author(s). Published by S. Karger AG, Basel } \\
\text { www.karger.com/cpb }\end{array}$ \\
\hline
\end{tabular} \\ He et al.: Prognostic Signature of Splicing Events in BLCA}

Cox proportional hazards regression revealed that only neoplasm cancer status, primary therapy outcome success and risk score (all) were independent prognostic indicators of BLCA survival (Table 4).

Clinical value of corresponding genes of SASEs used for prognostic signature construction

The counterpart genes of risk score (all) were B4GALT2, TMTC2, TIMM9, APOBEC3D, TPD52, MICU1, DDX11, and SMC6. mRNA expression of TMTC2 and MICU1 in tumor tissues was significantly lower than that in para-tumor tissues $(\mathrm{P}<0.05)$, while the mRNA expression of DDX11 and SMC6 were opposite (P $<0.05$ ). mRNA expression of B4GALT2, TIMM9, APOBEC3D, and TPD52 showed no considerable difference between tumor and para-tumor tissues (Fig. 4). Among the eight genes, TMTC2, DDX11, and SMC6 displayed poor efficiency for predicting survival status of BLCA patients by ROC analysis with AUC value $>0.8$ (Fig. 4). BLCA patients were divided into low- and high-risk groups according to the median value of mRNA expression of eight genes. However, the K-M analysis showed no difference in survival time between the two groups of BLCA patients (Fig. 4).

The PSI value of one splicing event is an intuitive ratio for calculating the efficiency of splicing of sequences of corresponding gene into transcripts $[13,14]$. Whether a potential relationship exists between the PSI value of the splicing event and mRNA expression of its counterpart remains largely unclear. In the present study, correlation analysis was performed between the PSIs of the 8 splicing events used for the construction of risk score (all) and the mRNA expression of corresponding genes (Fig. 5). Fig. 5A, 5C, and 5F showed that there was no significant correlation between the PSI value of the splicing event and mRNA expression of the corresponding genes; however, Fig. 5B, 5D, 5E, and 5G indicated a positive correlation and $\mathrm{Fig}$. $5 \mathrm{H}$ showed a negative correlation. These data suggested that there was no certain or potential relationship between the PSI value of the splicing event and mRNA expression of its counterpart gene.

Potential regulatory networks of SASEs between splicing factors and other genes

Splicing factors are RNA-binding proteins that regulate splicing events by recognizing

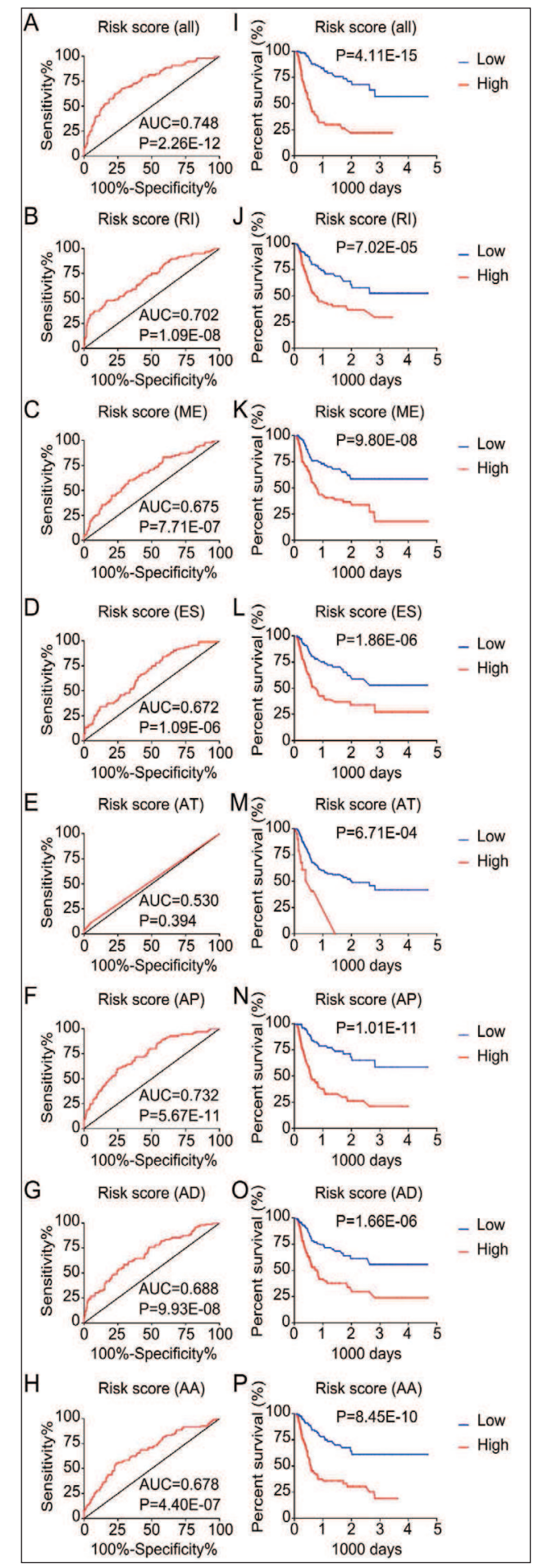

Fig. 3. ROC and K-M curves of eight risk scores constructed using SASEs in BLCA. (A-H) ROC curves of eight risk scores for predicting survival status of patients with BLCA, and (J-P) $\mathrm{K}-\mathrm{M}$ curves of eight risk scores in BLCA patients, divided into low- and high-risk groups based on the median value of the risk score. 


\section{Cellular Physiology Cell Physiol Biochem 2018;48:1355-1368 \begin{tabular}{ll|l} 
DOI: 10.1159/000492094 & $\begin{array}{l}\text { () 2018 The Author(s). Published by S. Karger AG, Basel } \\
\text { www.karger.com/cpb }\end{array}$
\end{tabular} \\ He et al.: Prognostic Signature of Splicing Events in BLCA}

cis-regulatory elements within the pre-mRNA to influence exon and splicing site selections [30]. Gene expression levels calculated from TCGA BLCA level 3 RNA-seq data identified 34 splicing factors whose gene expression levels differed significantly between para-tumor and tumour tissues (Fig. 6, Table $5)$. We were interested in whether the splicing events of differential expressed splicing factors could be potential regulators of SASEs in BLCA.

Among the 34 differentially expressed splicing factors, only ESRP1, HNRNPA2B1, HNRNPL, MBNL1, PTBP1, RBFOX2, SRSF2 and TIAL1 contained splicing events associated with OS, as determined using univariate Cox regression analysis $(\mathrm{P}<0.05$; data not shown). Correlation analysis showed that only the PSI value of ESRP1-ES-36041, ESRP1-ES-36042, ESRP1-ES-39145, RBFOX2ES-26347, SRSF2-RI-18003, SRSF2RI-18005, SRSF2-RI-18004 and TIAL1-ES-4679 were significantly associated with the expression values of ESRP1, RBFOX2, SRSF2, and TIAL1 ( $<$ < 0.05; data not shown).

Correlations between the PSIs of the 8 splicing events of the splicing factors mentioned above and the 66 SASEs of non-splicing factors (determined using univariate Cox regression analysis, $\mathrm{P}<0.0001$ ) were tested with Spearman's correlation coefficient. The correlation network was drawn by Cytoscape 3.5 (Fig. $6 \mathrm{~A})$, and only notable correlations were displayed $(\mathrm{P}<0.00001)$. In this network, the red quadrilateral nodes represent splicing events of splicing factors, the PSI value of which was positively correlated with the expression level of corresponding splicing factors $(\mathrm{P}<0.05)$, and the red diamond-shaped nodes represent negatively correlated splicing events of splicing factors. The PSIs for the 8 splicing events of the 4 splicing factors (red nodes) were remarkably correlated with the PSIs of 25 SASEs (blue nodes); 20 of these were significantly related to good survival in patients with BLCA (light blue quadrilateral nodes), and 5 were significantly related to poor survival in patients (light blue elliptical nodes). The green line indicates a positive correlation, while the blue line shows a negative correlation. Interestingly, the PSI value of ESRP1-ES-39145 was significantly positively correlated with
Table 3. Comparison of the K-M and ROC analysis among different prognostic signatures

\begin{tabular}{|c|c|c|c|c|c|}
\hline & & \multicolumn{2}{|c|}{$\mathrm{K}-\mathrm{M}$ analysis } & \multicolumn{2}{|c|}{ ROC analysis } \\
\hline & & Survival time (day) & $\mathrm{P}$ value & $\operatorname{AUC}(95 \% \mathrm{CI})$ & $\mathrm{P}$ value \\
\hline \multirow[t]{3}{*}{ All } & & & $4.10823 \mathrm{E}-15$ & $0.748(0.688-0.808)$ & $2.26 \mathrm{E}-12$ \\
\hline & low & $3304.841 \pm 239.758$ & & & \\
\hline & high & $1198.614 \pm 152.460$ & & & \\
\hline \multirow[t]{2}{*}{ RI } & & & 7.01999E-05 & $0.702(0.638-0.766)$ & $1.09 \mathrm{E}-08$ \\
\hline & $\begin{array}{l}\text { low } \\
\text { high }\end{array}$ & $\begin{array}{l}2996.300 \pm 246.428 \\
1572.148 \pm 153.255\end{array}$ & & & \\
\hline \multirow[t]{3}{*}{ ME } & & & $9.80085 \mathrm{E}-08$ & $0.675(0.610-0.739)$ & 7.71E-07 \\
\hline & low & $3138.232 \pm 229.414$ & & & \\
\hline & high & $1611.098 \pm 236.834$ & & & \\
\hline \multirow[t]{3}{*}{ ES } & & & $1.8582 \mathrm{E}-06$ & $0.672(0.609-0.734)$ & $1.19 \mathrm{E}-06$ \\
\hline & low & $3018.287 \pm 248.032$ & & & \\
\hline & high & $1838.069 \pm 235.096$ & & & \\
\hline \multirow[t]{2}{*}{ AT } & & & 0.000670781 & $0.530(0.460-0.601)$ & 0.394098 \\
\hline & low & $2517.922 \pm 182.059$ & & & \\
\hline \multirow[t]{3}{*}{ AP } & & & $1.01275 \mathrm{E}-11$ & $0.732(0.672-0.791)$ & $5.67 \mathrm{E}-11$ \\
\hline & low & $3275.606 \pm 237.452$ & & & \\
\hline & high & $1401.547 \pm 182.041$ & & & \\
\hline \multirow[t]{2}{*}{$\mathrm{AD}$} & & & $1.66417 \mathrm{E}-06$ & $0.688(0.624-0.752)$ & $9.93 \mathrm{E}-08$ \\
\hline & low & $3075.237 \pm 232.111$ & & & \\
\hline \multirow{3}{*}{ AA } & ingn & $1734.886 \pm 241.698$ & $8.45032 \mathrm{E}-10$ & $0.678(0.613-0.744)$ & $4.4 \mathrm{E}-07$ \\
\hline & low & $3248.832 \pm 224.944$ & & & \\
\hline & high & $1367.852 \pm 159.922$ & & & \\
\hline
\end{tabular}

Table 4. Prognostic value of related clinical parameters and risk score (all). Abbreviations: BMI, Body Mass Index; CRR, Complete Remission/Response; SD, Stable Disease; PRR, Partial Remission/Response; PD, Progressive Disease

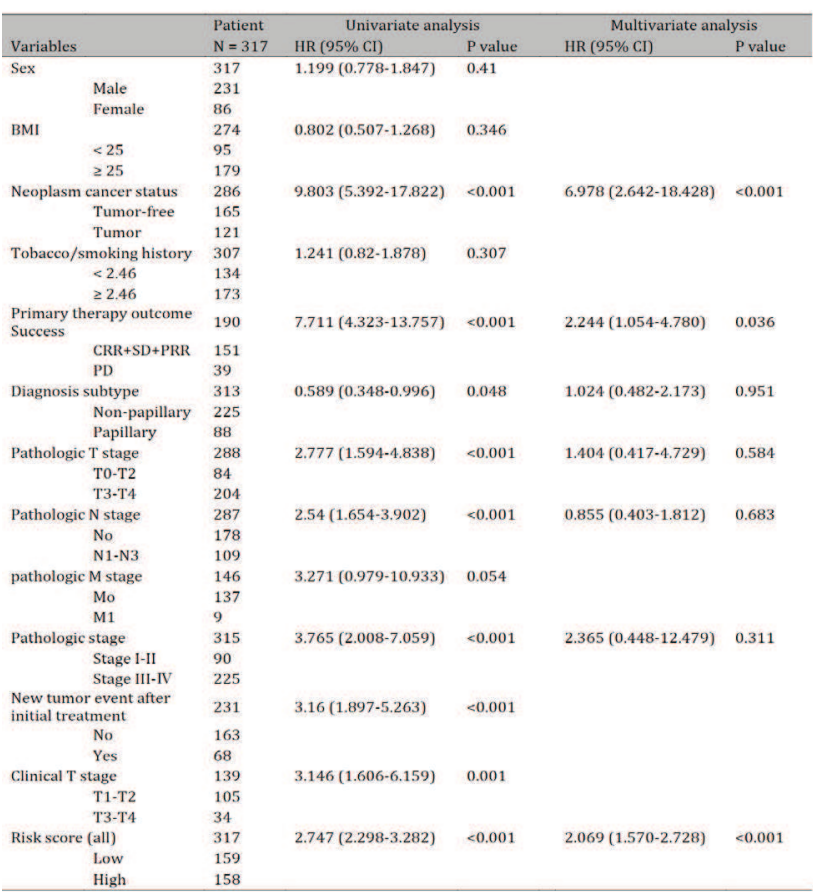




\section{Cellular Physiology Cell Physiol Biochem 2018;48:1355-1368 \begin{tabular}{l|l} 
DOI: 10.1159/000492094 & $\begin{array}{l}\text { () 2018 The Author(s). Published by S. Karger AG, Basel } \\
\text { www.karger.com/cpb }\end{array}$
\end{tabular} He et al. Prognostic Signature of Splicing Events in BLCA}

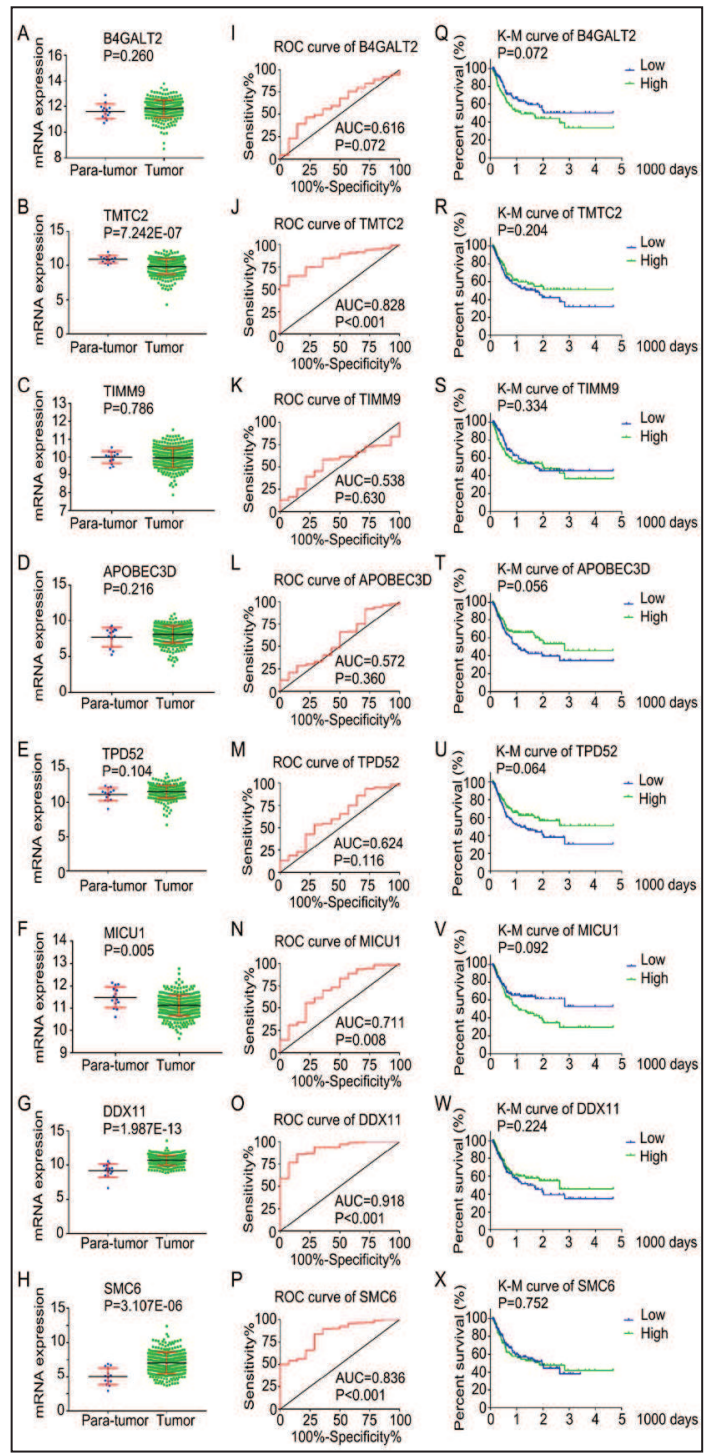

Fig. 4. mRNA expression, ROC curves, and K-M curves of genes from the eight splicing events used in constructing "risk score (all)" in BLCA. (A-H) mRNA expression of eight genes between paratumor and tumor tissues. (I-P) ROC curves of eight genes for predicting survival status of patients with BLCA. Among the eight genes, TMTC2, TIMM9, and MICU1 were predictive for alive status, while B4GALT2, APOBEC3D, TPD52, DDX11, and SMC6 were predictive for dead status. (Q-X) K-M curves of eight genes in BLCA patients, divided into lowand high-risk groups according to the median value of mRNA expression of eight genes.

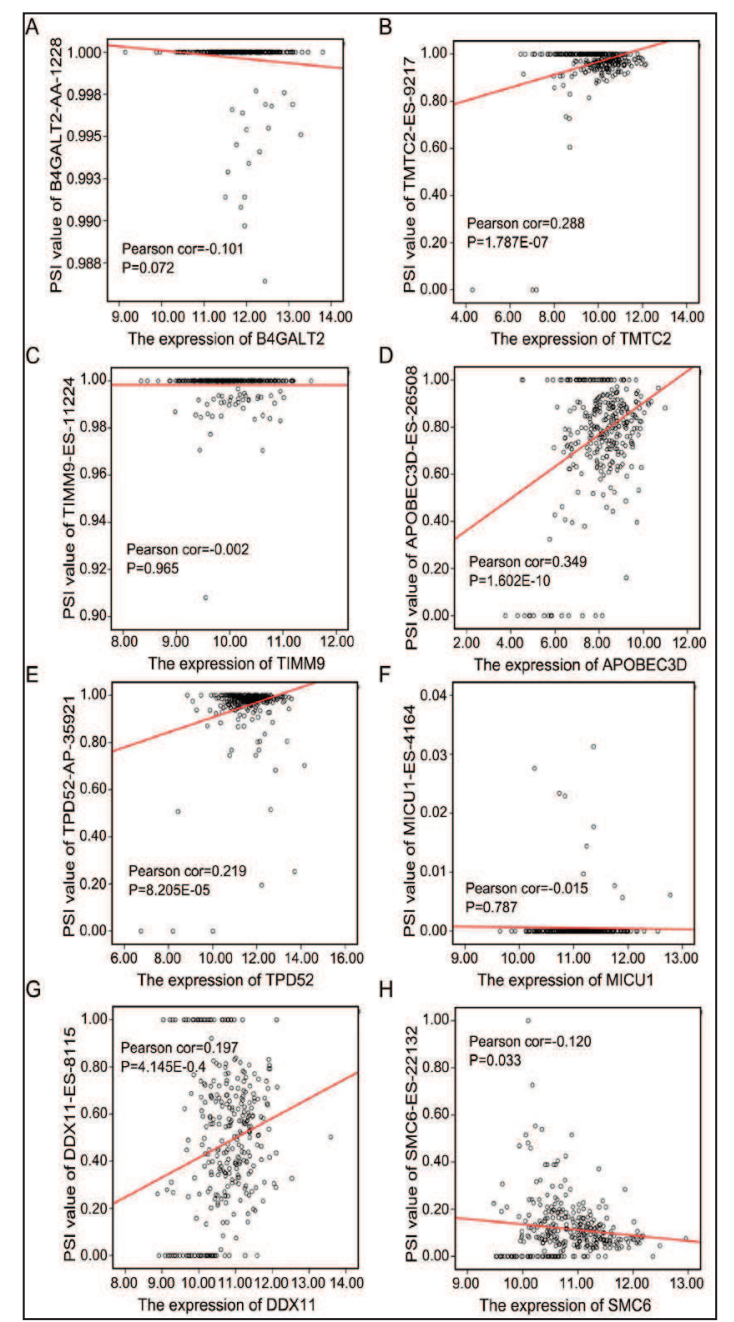

Fig. 5. Correlation analysis between the PSI of a splicing event and the mRNA expression of its counterpart gene. (A) B4GALT2-AA-1228 and B4GALT2. (B) TMTC2-ES-9217 and TMTC2. (C) TIMM9-ES-11224 and TIMM9. (D) APOBEC3DES-26508 and APOBEC3D. (E) TPD52-AP-35921 and TPD52. (F) MICU1-ES-4164 and MICU1. (G) DDX11ES-8115 and DDX11. (H) SMC6-ES-22132 and SMC6.

the PSI value of EPCAM-AD-22525 while the other two splicing events of ESRP1 were not (Fig. $6 \mathrm{~A}$ ), suggesting that different splicing events of splicing factors may have different functions. ESRP1 expression level was prominently higher in tumor tissues than in para-tumor tissues (Fig. 6B). ESRP1 expression was positively associated with the PSI value of ESRP1-ES-39145 
\begin{tabular}{cc|c} 
Cellular Physiology & Cell Physiol Biochem 2018;48:1355-1368 \\
\cline { 2 - 3 } $\begin{array}{c}\text { DOI: 10.1159/000492094 } \\
\text { and Biochemistry }\end{array}$ & $\begin{array}{l}\text { O 2018 The Author(s). Published by S. Karger AG, Basel } \\
\text { www.karger.com/cpb }\end{array}$ \\
\cline { 2 - 3 } &
\end{tabular}

He et al.: Prognostic Signature of Splicing Events in BLCA

(Fig. 6C), which was remarkably associated with poor survivalrelated splicing event of TGIF1AP-18503 (Fig. 6D).

\section{Discussion}

In BLCA, the function or prognostic values of single alternative splicing events of genes have been well studied [25, 31-34], but no systematic assessment of the prognostic value of splicing events has been reported. Benefiting from the contribution of TCGA SpliceSeq database, SASEs in BLCA were identified using univariate Cox regression analysis. Among the risk scores constructed based on all type, RI-type, ME-type, EStype, AT-type, AP-type, AD-type, and AA-type of SASEs, risk score (all) exhibited an impressive efficiency for predicting the prognosis of patients with BLCA. The PSIs for the splicing events were remarkably correlated with mRNA expression of corresponding genes, such as TMTC2, APOBEC3D, TPD52, DDX11, and SMC6. Finally, the potential regulatory network with SASEs of splicing factors and other genes was constructed.

Previous research based on TCGA data on prognostic factors showed similar efficiency. For example, the AUC of ROC analysis of the risk score constructed using three genes, RCOR1, ST3GAL5, and COL1OA1 was 0.647 for predicting survival of BLCA patients [35]. Bao et al. reported that the AUC of four long non-coding RNA prognostic signatures was 0.807 for predicting 5-year survival in patients with BLCA [36]. Zhou et al. showed that the AUC value of eight microRNA prognostic signatures was 0.74
Table 5. Comparison of mRNA expression levels of 34 splicing factors between normal and tumor tissues

\begin{tabular}{|c|c|c|c|c|c|}
\hline Splicing factor & Tissue & $\mathrm{N}$ & Mean & Std. deviation & $P$ value \\
\hline \multirow[t]{2}{*}{ CELF1 } & tumor & 317 & 12.38227 & 0.365735199 & 0.036304 \\
\hline & normal & 14 & 12.5932 & 0.406091465 & \\
\hline \multirow[t]{2}{*}{ RBFOX2 } & tumor & 317 & 11.97122 & 0.56889487 & 0.003122 \\
\hline & normal & 14 & 12.78509 & 0.840408522 & \\
\hline \multirow[t]{2}{*}{ Hnrnpa2b1 } & tumor & 317 & 15.33619 & 0.37635422 & $6.52 \mathrm{E}-05$ \\
\hline & normal & 14 & 14.92273 & 0.318742082 & \\
\hline \multirow[t]{2}{*}{ PTBP1 } & tumor & 317 & 13.96962 & 0.349833885 & 0.000365 \\
\hline & normal & 14 & 13.26524 & 0.55361328 & \\
\hline \multirow[t]{2}{*}{ ELAVL4 } & tumor & 302 & 2.140681 & 2.603801619 & 0.02853 \\
\hline & normal & 14 & 2.802092 & 0.904444004 & \\
\hline \multirow[t]{2}{*}{ ELAVL1 } & tumor & 317 & 12.21484 & 0.36319966 & 0.003545 \\
\hline & normal & 14 & 11.92603 & 0.272166324 & \\
\hline \multirow[t]{2}{*}{ NOVA1 } & tumor & 317 & 4.68902 & 2.114382369 & $3.34 \mathrm{E}-10$ \\
\hline & normal & 14 & 8.748374 & 1.117093539 & \\
\hline \multirow[t]{2}{*}{ SRSF1 } & tumor & 317 & 13.19774 & 0.350211396 & 0.000215 \\
\hline & normal & 14 & 12.84127 & 0.311857502 & \\
\hline \multirow[t]{2}{*}{ KHDRBS2 } & tumor & 262 & -0.42358 & 3.379118039 & 0.000161 \\
\hline & normal & 14 & 3.077496 & 2.269261808 & \\
\hline \multirow[t]{2}{*}{ KHDRBS3 } & tumor & 317 & 7.455356 & 1.780657049 & 0.006837 \\
\hline & normal & 14 & 8.765983 & 1.265744831 & \\
\hline \multirow[t]{2}{*}{ SRSF3 } & tumor & 317 & 13.75171 & 0.32977084 & 0.016625 \\
\hline & normal & 14 & 13.97272 & 0.46560996 & \\
\hline \multirow[t]{2}{*}{ TARDBP } & tumor & 317 & 12.58425 & 0.265394072 & 0.025067 \\
\hline & normal & 14 & 12.42137 & 0.255312732 & \\
\hline RBFOX1 & tumor & 239 & -0.50215 & 3.638765636 & 0.005042 \\
\hline & normal & 14 & 2.29848 & 2.793003885 & \\
\hline PCBP1 & tumor & 317 & 12.98737 & 0.493976536 & 0.002335 \\
\hline & normal & 14 & 13.23697 & 0.242882451 & \\
\hline HTRA2 & tumor & 317 & 10.23325 & 0.525480586 & 0.012166 \\
\hline & normal & 14 & 9.87576 & 0.331643685 & \\
\hline KHSRP & tumor & 317 & 13.30265 & 0.413706165 & $1.2 \mathrm{E}-05$ \\
\hline & normal & 14 & 12.93693 & 0.210986618 & \\
\hline РTBP2 & tumor & 317 & 9.377024 & 0.616121046 & 0.009156 \\
\hline & normal & 14 & 10.32861 & 1.161932501 & \\
\hline SRSF2 & tumor & 317 & 12.94809 & 0.345383284 & 0.011634 \\
\hline & normal & 14 & 12.5117 & 0.554838484 & \\
\hline SRSF9 & tumor & 317 & 12.18938 & 0.44409823 & 0.00163 \\
\hline & normal & 14 & 11.52253 & 0.629812996 & \\
\hline SRSF10 & tumor & 317 & 12.13925 & 0.390249872 & $3.48 \mathrm{E}-05$ \\
\hline & normal & 14 & 11.78705 & 0.221512357 & \\
\hline SRSF5 & tumor & 317 & 12.94702 & 0.575824743 & $2.36 \mathrm{E}-05$ \\
\hline & normal & 14 & 13.61894 & 0.516175105 & \\
\hline TIA1 & tumor & 317 & 11.94634 & 0.640664741 & 7.07E-06 \\
\hline & normal & 14 & 11.3422 & 0.333490542 & \\
\hline CELF2 & tumor & 317 & 8.426049 & 1.643790086 & $7.19 \mathrm{E}-11$ \\
\hline & normal & 14 & 11.4258 & 1.254042498 & \\
\hline SYNCRIP & tumor & 317 & 12.98103 & 0.492150387 & 0.004195 \\
\hline & normal & 14 & 13.3663 & 0.413724173 & \\
\hline DAZAP1 & tumor & 317 & 12.85574 & 0.385617979 & $1.39 \mathrm{E}-09$ \\
\hline & normal & 14 & 12.20281 & 0.328513236 & \\
\hline hnRNPL & tumor & 317 & 13.47598 & 0.337513443 & $4.91 \mathrm{E}-06$ \\
\hline & normal & 14 & 13.04928 & 0.306008748 & \\
\hline QKI & tumor & 317 & 11.52298 & 0.711046843 & 0.002293 \\
\hline & normal & 14 & 12.12111 & 0.749474298 & \\
\hline hnRNPLL & tumor & 317 & 10.59023 & 0.341093665 & 0.012298 \\
\hline & normal & 14 & 10.82675 & 0.409158513 & \\
\hline hnRNPH3 & tumor & 317 & 12.55756 & 0.389053773 & 0.003919 \\
\hline & normal & 14 & 12.86576 & 0.37359275 & \\
\hline hnRNPH2 & tumor & 317 & 12.04993 & 0.411811004 & 0.000425 \\
\hline & normal & 14 & 12.44543 & 0.253869353 & \\
\hline SF1 & tumor & 317 & 13.33032 & 0.328148007 & 4.13E-05 \\
\hline & normal & 14 & 13.70916 & 0.449262313 & \\
\hline MBNL1 & tumor & 317 & 12.24883 & 0.585472427 & 0.002811 \\
\hline & normal & 14 & 13.32046 & 1.090792493 & \\
\hline TIAL1 & tumor & 317 & 11.82653 & 0.377957895 & 0.000145 \\
\hline & normal & 14 & 11.60273 & 0.160685808 & \\
\hline ESRP1 & tumor & 317 & 12.46394 & 1.612698525 & 0.037406 \\
\hline & normal & 14 & 8.878575 & 5.782591975 & \\
\hline
\end{tabular}




\section{Cellular Physiology \\ Cell Physiol Biochem 2018;48:1355-1368 and Biochemistry

Fig. 6. Correlation between splicing events of splicing factors and survival-related splicing events in BLCA. (A) Correlation network of splicing events between splicing factors and other genes. (B) ESRP1 expression in normal and tumor tissues. (C) Dot plot of the correlation between ESRP1 expression and the PSI for ESRP1-ES-39145. (D) Dot plot of the correlation between the PSI for ESRP1-ES-39145 and that for TGIF1-AP-18503.

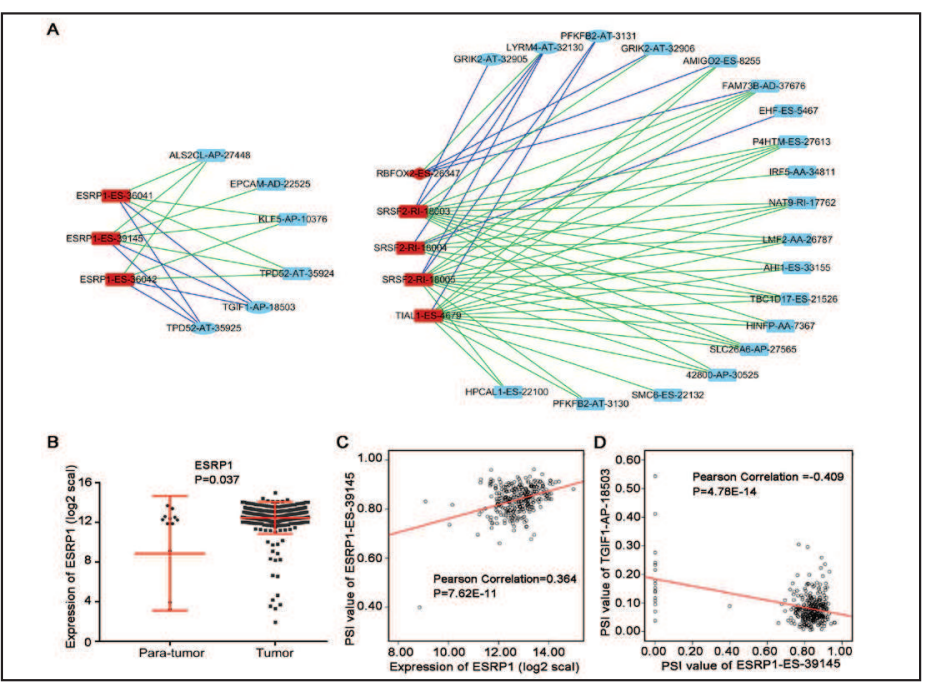

for predicting survival of patients with BLCA [37]. In our study, of all the risk scores built by SASEs, the risk scores (all) showed the highest AUC value of 0.748 for predicting survival of BLCA patients, the AUC value of which still attaining a reasonable efficiency of prognostic value. Thus, our work could also contribute to elucidating the molecular mechanisms involved in BLCA.

Splicing events can be detected using quantitative polymerase chain reaction or Northern Blot techniques. Several studies have reported the detection of splicing events or splicing variants in urine sample of patients with BLCA. For example, good diagnostic performance of splicing variants of carbonic anhydrase IX in urine sediments was discovered with AUC $=0.891$ [38]. CD44 splice variants were highly expressed in $90 \%(18 / 20)$ of urine samples from BLCA patients, but no expression was detected in urine samples from the 20 controls [39]. Nevertheless, no studies about the detection of splicing variants of B4GALT2, TMTC2, TIMM9, APOBEC3D, TPD52, MICU1, DDX11, and SMC6 in urine have been published. The urinary expression of splicing variants of these genes in BLCA patients could be used to evaluate their clinical value.

Li et al [4]. performed the first genome-wide analysis of splicing events with TCGA RNA-seq data and constructed prognostic models based on SASEs to predict the prognosis of patients with non-small cell lung cancer. Our current work is the first to provide a comprehensive understanding of alternative splicing events and risk scores based on SASEs for predicting the prognosis of BLCA patients. The prognostic value of splicing events of well-known cancer-associated genes such as EGFR and MKL1 in lung adenocarcinoma and MAPKAP1 and $A R$ in lung squamous cell carcinoma have been demonstrated [4]. In addition, Li et al [4]. constructed a potential regulatory network between splicing factors and alternative splicing events, but the results may not reflect the actual situation because increasing evidence has revealed varying, even opposing, functions of transcripts from the same genes from alternative splicing [9, 40-42]. In the present study, we have provided a more accurate potential regulatory network. SASEs of splicing factors were identified, and the corresponding PSIs were used for correlation analysis with the PSIs for the SASEs of other genes. Only notable correlations with a P value less than 0.00001 were displayed in the regulatory network.

The potential regulatory network of SASEs in this study showed the complex correlation between the splicing events of splicing factors and non-splicing factors. For example, ESRP1ES-36041 may promote the occurrence of ALS2CL-AP-27448, EPCAM-AD-22525, and KLF5AP-10376 and suppress the splicing of TGIF1-AP-18503 and TPD52-AT-35925, indicating that ESRP1-ES-36041 may play different roles depending on its splicing targets. Also, the splicing factor of ESRP1 contained several SASEs, but the functions of these SASEs could 


\section{Cellular Physiology Cell Physiol Biochem 2018:48:1355-1368 \begin{tabular}{ll|l} 
DOI: 10.1159/000492094 & $\begin{array}{l}\text { () } 2018 \text { The Author(s). Published by S. Karger AG, Basel } \\
\text { www.karger.com/cpb }\end{array}$
\end{tabular}}

He et al.: Prognostic Signature of Splicing Events in BLCA

be distinct. Therefore, mRNA expression of a gene may not be accurate enough to reflect the function of the gene and the biological function of genes may be dependent on their predominant splicing events.

Splicing factors were thought to be crucial in tumor invasion and migration [43]. In this study, we identified aberrant expression of 34 splicing factors in BLCA, and the functions of these aberrantly expressed splicing factors needed to be elucidated. The potential regulatory relationship between the splicing events of splicing factors and non-splicing factors were also established. However, the potential regulatory network of splicing events of splicing factors remains unclear, and whether the splicing events of splicing factors differ notably in tumor tissues compared with the para-tumor tissues also needs to be explored further. Therefore, clarifying the function of alternative splicing from several perspectives is vital in the interpretation of the mechanism of BLCA. More attention should thus be paid to the study of alternative splicing.

In conclusion, we have provided comprehensive picture of splicing events in patients with BLCA and identified SASEs, which were used to construct of prognostic signatures. We also built a potential regulatory network of splicing events of splicing factors and other genes. This work may provide a new prognostic indicator of outcomes in BLCA patients and broaden the understanding of alternative splicing in BLCA.

\section{Abbreviations}

BLCA (bladder urothelial carcinoma); TCGA (The Cancer Genome Atlas); K-M (KaplanMeier); AUC (area under the curve); ROC (receiver operator characteristic); PSI (percent spliced-in index); ES (exon skip); ME (mutually exclusive exons); RI (retained intron); AP (alternate promoter); AT (alternate terminator); AD (alternate donor site); AA (alternate acceptor site); DAVID (Database for Annotation, Visualization and Integrated Discovery); GO (Gene Ontology); CC (cellular component); MF (molecular function); BP (biological process); KEGG (Kyoto Encyclopedia of Genes and Genomes); C16orf74 (chromosome 16 open reading frame 74); OS (overall survival); SASEs (survival-associated splicing events); CD44 (CD44 molecule (Indian blood group)); TMTC2 (transmembrane and tetratricopeptide repeat containing 2); APOBEC3D (apolipoprotein B mRNA editing enzyme catalytic subunit 3D); TPD52 (tumor protein D52); DDX11 (DEAD/H-box helicase 11); SMC6 (structural maintenance of chromosomes 6); PSMC5 (proteasome 26S subunit, ATPase 5); CDK2 (cyclin dependent kinase 2); VEGFA (vascular endothelial growth factor A); $\mathrm{CDH1}$ (cadherin 1); CTBP1 (C-terminal binding protein 1); CASP8 (caspase 8); UBE2K (ubiquitin conjugating enzyme E2 K); FBXW7 (F-box and WD repeat domain containing 7).

\section{Acknowledgements}

The study was supported by the International Communication of Guangxi Medical University Graduate Education (2017), the Promoting Project of Basic Capacity for Young and Middle-aged University Teachers in Guangxi (KY2016YB090), the Guangxi Medical University Training Program for Distinguished Young Scholars, the Guangxi Natural Science Fund for Innovation Research Team (2013GXNSFFA019002, 2016GXNSFGA380006), the Science and Technology Development Plan of Guangxi (Guikegong 1355005-3-17), and the Guangxi Natural Science Foundation (2016GXNSFBA380150).

\section{Disclosure Statement}

No conflict of interests exists. 


\section{Cellular Physiology Cell Physiol Biochem 2018;48:1355-1368 \begin{tabular}{l|l} 
DOI: 10.1159/000492094 218 & $\begin{array}{l}\text { C 2018 The Author(s). Published by S. Karger AG, Basel } \\
\text { www.karger.com/cpb }\end{array}$ \\
\hline
\end{tabular}}

He et al.: Prognostic Signature of Splicing Events in BLCA

\section{References}

1 Salton M, Misteli T: Small Molecule Modulators of Pre-mRNA Splicing in Cancer Therapy. Trends Mol Med 2016;22:28-37.

2 Warns JA, Davie JR, Dhasarathy A: Connecting the dots: chromatin and alternative splicing in EMT. Biochem Cell Biol 2016;94:12-25.

-3 Narayanan SP, Singh S, Shukla S: A saga of cancer epigenetics: linking epigenetics to alternative splicing. The Biochemical journal 2017;474:885-896.

4 Li Y, Sun N, Lu Z, Sun S, Huang J, Chen Z, He J: Prognostic alternative mRNA splicing signature in non-small cell lung cancer. Cancer Lett 2017;393:40-51.

-5 Xiong W, Gao D, Li Y, Liu X, Dai P, Qin J, Wang G, Li K, Bai H, Li W: Genome-wide profiling of chemoradiationinduced changes in alternative splicing in colon cancer cells. Oncol Rep 2016;36:21422150.

-6 Aversa R, Sorrentino A, Esposito R, Ambrosio MR, Amato A, Zambelli A, Ciccodicola A, D’Apice L, Costa V: Alternative Splicing in Adhesion- and Motility-Related Genes in Breast Cancer. Int J Mol Sci 2016;17

7 He X, Yuan C, Yang J: Regulation and functional significance of CDC42 alternative splicing in ovarian cancer. Oncotarget 2015;6:29651-29663.

8 Wan L, Yu W, Shen E, Sun W, Liu Y, Kong J, Wu Y, Han F, Zhang L, Yu T, Zhou Y, Xie S, Xu E, Zhang H, Lai M: SRSF6-regulated alternative splicing that promotes tumour progression offers a therapy target for colorectal cancer. Gut 2017;0:1-12.

-9 Kim CJ, Terado T, Tambe Y, Mukaisho KI, Sugihara H, Kawauchi A, Inoue H: Anti-oncogenic activities of cyclin D1b siRNA on human bladder cancer cells via induction of apoptosis and suppression of cancer cell stemness and invasiveness. Int J Oncol 2017;52:231-240.

10 Le KQ, Prabhakar BS, Hong WJ, Li LC: Alternative splicing as a biomarker and potential target for drug discovery. Acta Pharmacol Sin 2015;36:1212-1218.

-11 Sveen A, Kilpinen S, Ruusulehto A, Lothe RA, Skotheim RI: Aberrant RNA splicing in cancer; expression changes and driver mutations of splicing factor genes. Oncogene 2016;35:2413-2427.

12 Feng H, Qin Z, Zhang X: Opportunities and methods for studying alternative splicing in cancer with RNASeq. Cancer Lett 2013;340:179-191.

13 Ryan MC, Cleland J, Kim R, Wong WC, Weinstein JN: SpliceSeq: a resource for analysis and visualization of RNA-Seq data on alternative splicing and its functional impacts. Bioinformatics 2012;28:2385-2387.

14 Schafer S, Miao K, Benson CC, Heinig M, Cook SA, Hubner N: Alternative Splicing Signatures in RNA-seq Data: Percent Spliced in (PSI). Curr Protoc Hum Genet 2015;87:11.16.1- 11.16.14.

15 Kamat AM, Hahn NM, Efstathiou JA, Lerner SP, Malmstrom PU, Choi W, Guo CC, Lotan Y, Kassouf W: Bladder cancer. Lancet 2016;388:2796-2810.

16 Siegel RL, Miller KD, Jemal A: Cancer Statistics, 2017. CA Cancer J Clin 2017;67:7-30.

17 Gao L, Li SH, Tian YX, Zhu QQ, Chen G, Pang YY, Hu XH: Role of downregulated miR-133a-3p expression in bladder cancer: a bioinformatics study. Onco Targets Ther 2017;10:3667-3683.

18 Wei Y, He R, Wu Y, Gan B, Wu P, Qiu X, Lan A, Chen G, Wang Q, Lin X, Chen Y, Mo Z: Comprehensive investigation of aberrant microRNA profiling in bladder cancer tissues. Tumour Biol 2016;37:1255512569.

19 Sun DK, Wang JM, Zhang P, Wang YQ: MicroRNA-138 Regulates Metastatic Potential of Bladder Cancer Through ZEB2. Cell Physiol Biochem 2015;37:2366-2374.

20 Zhang X, Yang X, Yang C, Li P, Yuan W, Deng X, Cheng Y, Li P, Yang H, Tao J, Lu Q: Targeting protein kinase CK2 suppresses bladder cancer cell survival via the glucose metabolic pathway. Oncotarget 2016;7:8736187372.

21 Gan X, Lin X, He R, Lin X, Wang H, Yan L, Zhou H, Qin H, Chen G: Prognostic and Clinicopathological Significance of Downregulated p16 Expression in Patients with Bladder Cancer: A Systematic Review and Meta-Analysis. Dis Markers 2016;2016:1-13.

22 Chang IW, Lin VC, He HL, Hsu CT, Li CC, Wu WJ, Huang CN, Wu TF, Li CF: CDCA5 overexpression is an indicator of poor prognosis in patients with urothelial carcinomas of the upper urinary tract and urinary bladder. Am J Transl Res 2015;7:710-722. 


\section{Cellular Physiology Cell Physiol Biochem 2018;48:1355-1368 \begin{tabular}{l|l} 
DOI: 10.1159/000492094 218 & $\begin{array}{l}\text { C 2018 The Author(s). Published by S. Karger AG, Basel } \\
\text { www.karger.com/cpb }\end{array}$ \\
\hline
\end{tabular}}

He et al.: Prognostic Signature of Splicing Events in BLCA

23 Luo Y, Zhang X, Mo M, Tan Z, Huang L, Zhou H, Wang C, Wei F, Qiu X, He R, Chen G: High Ki-67 Immunohistochemical Reactivity Correlates With Poor Prognosis in Bladder Carcinoma: A Comprehensive Meta-Analysis with 13, 053 Patients Involved. Medicine (Baltimore) 2016;95:e3337.

24 Hussain SA, Palmer DH, Syn WK, Sacco JJ, Greensmith RM, Elmetwali T, Aachi V, Lloyd BH, Jithesh PV, Arrand J, Barton D, Ansari J, Sibson DR, James ND: Gene expression profiling in bladder cancer identifies potential therapeutic targets. Int J Oncol 2017;50:1147-1159.

-25 Poursani EM, Mehravar M, Mohammad Soltani B, Mowla SJ, Trosko JE: A Novel Variant of OCT4 Entitled OCT4B3 is Expressed in Human Bladder Cancer and Astrocytoma Cell Lines. Avicenna J Med Biotechnol 2017;9:142-145.

26 Gosalbez M, Hupe MC, Lokeshwar SD, Yates TJ, Shields J, Veerapen MK, Merseburger AS, Rosser CJ, Soloway MS, Lokeshwar VB: Differential expression of SDF-1 isoforms in bladder cancer. J Urol 2014;191:18991905.

27 Konstantakou EG, Voutsinas GE, Velentzas AD, Basogianni AS, Paronis E, Balafas E, Kostomitsopoulos N, Syrigos KN, Anastasiadou E, Stravopodis DJ: 3-BrPA eliminates human bladder cancer cells with highly oncogenic signatures via engagement of specific death programs and perturbation of multiple signaling and metabolic determinants. Mol Cancer 2015;14:135.

28 Lex A, Gehlenborg N, Strobelt H, Vuillemot R, Pfister H: UpSet: Visualization of Intersecting Sets. IEEE Trans Vis Comput Graph 2014;20:1983-1992.

-29 Piva F, Giulietti M, Burini AB, Principato G: SpliceAid 2: a database of human splicing factors expression data and RNA target motifs. Hum Mutat 2012;33:81-85.

30 Fredericks AM, Cygan KJ, Brown BA, Fairbrother WG: RNA-Binding Proteins: Splicing Factors and Disease. Biomolecules 2015;5:893-909.

-31 Ishiwata T: Role of fibroblast growth factor receptor-2 splicing in normal and cancer cells. Front Biosci (Landmark Ed) 2018;23:626-639.

32 Han B, Shen Y, Zhang P, Jayabal P, Che R, Zhang J, Yu H, Fei P: Overlooked FANCD2 variant encodes a promising, portent tumor suppressor, and alternative polyadenylation contributes to its expression. Oncotarget 2017;8:22490-22500.

- 33 Arnold SA, Loomans HA, Ketova T, Andl CD, Clark PE, Zijlstra A: Urinary oncofetal ED-A fibronectin correlates with poor prognosis in patients with bladder cancer. Clin Exp Metastasis 2016;33:29-44.

-34 Tomlinson DC, Knowles MA: Altered splicing of FGFR1 is associated with high tumor grade and stage and leads to increased sensitivity to FGF1 in bladder cancer. Am J Pathol 2010;177:2379-2386.

-35 Liu Q Diao R, Feng G, Mu X, Li A: Risk score based on three mRNA expression predicts the survival of bladder cancer. Oncotarget 2017;8:61583-61591.

36 Bao Z, Zhang W, Dong D: A potential prognostic lncRNA signature for predicting survival in patients with bladder urothelial carcinoma. Oncotarget 2017;8:10485-10497.

-37 Zhou H, Tang K, Xiao H, Zeng J, Guan W, Guo X, Xu H, Ye Z: A panel of eight-miRNA signature as a potential biomarker for predicting survival in bladder cancer. J Exp Clin Cancer Res 2015;34:53.

-38 Malentacchi F, Vinci S, Della Melina A, Kuncova J, Villari D, Giannarini G, Nesi G, Selli C, Orlando C: Splicing variants of carbonic anhydrase IX in bladder cancer and urine sediments. Urol Oncol 2012;30:278-284.

-39 Wu Z, Zhang Y, Liu D: [Diagnostic value of CD44 splice variants in urine exfoliated cells of bladder cancer]. Zhonghua Wai Ke Za Zhi 1997;35:533-535.

-40 Alexandraki KI, Philippou A, Boutzios G, Theohari I, Koutsilieris M, Delladetsima IK, Kaltsas GA: IGF-IEc expression is increased in secondary compared to primary foci in neuroendocrine neoplasms. Oncotarget 2017;8:79003-79011.

-41 Ryu JY, Kim HU, Lee SY: Framework and resource for more than 11, 000 gene-transcript-protein-reaction associations in human metabolism. Proceedings of the National Academy of Sciences of the United States of America 2017;114:E9740-E9749.

-42 Krishnaswamy S, Mohammed AK, Tripathi G, Alokail MS, Al-Daghri NM: Splice variants of the extracellular region of RON receptor tyrosine kinase in lung cancer cell lines identified by PCR and sequencing. BMC Cancer 2017;17:738.

43 Chen L, Yao Y, Sun L, Zhou J, Miao M, Luo S, Deng G, Li J, Wang J, Tang J: Snail Driving Alternative Splicing of CD44 by ESRP1 Enhances Invasion and Migration in Epithelial Ovarian Cancer. Cell Physiol Biochem 2017;43:2489-2504. 